Article

\title{
Analytical Determination of Medical Gases Consumption and Their Impact on Hospital Sustainability
}

\author{
Miguel Gómez-Chaparro ${ }^{1}$, Justo García-Sanz-Calcedo ${ }^{2, *(\mathbb{D})}$ and Luis Armenta Márquez ${ }^{1}$ \\ 1 HM Hospitals, 28015 Madrid, Spain; mgomezchaparro@hmhospitales.com (M.G.-C.); \\ larmenta@hmhospitales.com (L.A.M.) \\ 2 Industrial Engineering School, University of Extremadura, 06007 Badajoz, Spain \\ * Correspondence: jgsanz@unex.es; Tel.: +34-924-289-300
}

Received: 9 July 2018; Accepted: 17 August 2018; Published: 20 August 2018

check for updates

\begin{abstract}
Medical gases are known to show a great environmental impact and also to consume relevant resources in terms of hospital management. The present work reports on a study performed between 2008 and 2016 in a target set of 12 Spanish hospitals with floor area and number of beds ranging 2314-23,300 $\mathrm{m}^{2}$ and 20-194, respectively, for which the average annual consumption rates of oxygen, nitrogen, medicinal air, carbon dioxide and nitrogen protoxide were analysed. The annual consumption of medical gases in a hospital was proved to be correlated with the number of hospital discharges, the number of surgeries, the number of emergency interventions, the number of hospitalisations, the number of hospital beds, the useful floor area of the building and the number of workers. In particular, the annual consumption per hospital bed was computed as $350 \mathrm{~m}^{3}$ for oxygen, $325 \mathrm{~m}^{3}$ for medicinal air, $9 \mathrm{~m}^{3}$ for nitrogen protoxide and $3 \mathrm{~m}^{3}$ for carbon dioxide. It is shown that healthcare activity appears as an adequate variable to quantify and to monitor medical gases consumption in hospitals, to assess the size of their facilities as well as to optimise maintenance management.
\end{abstract}

Keywords: healthcare facilities; medical gases; gas facilities; healthcare engineering; hospital sustainability

\section{Introduction}

The use of medical gases is essential for adequate medical interventions in hospitals and health centres provided their advantageous anaesthetic, analgesic and respiratory properties in the ambit of disease diagnosis, treatment, prevention or relief. Accordingly, they are currently classified as special medicines [1].

As referred to hospitals, the most widely used medical gases are the following: Oxygen $\left(\mathrm{O}_{2}\right)$, nitrogen $\left(\mathrm{N}_{2}\right)$, medicinal air, carbon dioxide $\left(\mathrm{CO}_{2}\right)$ and nitrogen protoxide $\left(\mathrm{N}_{2} \mathrm{O}\right)$, for all of which efficient and safe supply is guaranteed by the existence of specific facilities.

Medical oxygen is mainly used for the treatment and prevention of respiratory failure. In fact, oxygen therapy is regarded as the most demanded therapeutic intervention in hospitals [2].

Medicinal air is used in intensive care units via pulmonary nebulizers to prevent hyperoxia either in the lungs or in any other corporal tissue during mechanical ventilation or surgery interventions. It is obtained by a former compression of volumes of purified atmospheric air and a subsequent filtering of the $21 \% / 79 \%$ oxygen-nitrogen mix [3]. Both operations need to be carried out in a bacteriologically suitable and particle-free environment, and also in absence of oil or water traces.

The main application regarding medicinal nitrogen lies in the production of synthetic medicinal air by appropriate mixing with oxygen in specific gas mixers [4]. Moreover, it is also used for 
cryopreservation of cells, tissues and some other biological samples, as well as for particular interventions in the ambit of cryosurgery.

On another note, nitrogen protoxide acts as a co-adjuvant substance for general anaesthesia together with some other agents, and it is also used as an analgesic agent itself through inhalation [5]. Other anaesthetic gases used are halothane, enflurane, isoflurane, isoflurane, sevoflurane and desflurane. Carbon dioxide is used for laparoscopy interventions in minimally invasive surgeries and is also widely used in the fields of cryotherapy and cryosurgery due to its cooling ability.

The installation of medical gases equipment is a key factor in the management of buildings in the ambit of health assistance [6]. This point is well-known by professionals in hospital engineering, who are responsible for the implementation of actions devoted to management optimisation, to the increase of the useful life of facilities and to the reduction of operating costs [7]. Oxygen, nitrogen, carbon dioxide and nitrogen protoxide can be handled either as stored gas cylinders or also as liquid volumes supplied by tankers. For buildings involving high consumption rates, the medical gases supplier usually assumes the costs associated to supply, installation and rental of cryogenic tanks [8].

The installation of medical gas facilities in health assistance buildings require a variety of storing and distribution equipment: Portable gas cylinders, single cylinders batteries, cryogenic tanks and specific devices for self-production of medical air [9].

Ozaeta et al. (2017) reported on the viability of automation of medical gas systems in the dialysis department of a 400-bed hospital [10], to finally suggest a lack of preventive monitoring and control of costs which might have helped optimise the handling of medical gases.

Zelaya (2013) established a list of criteria to design supply and distribution systems of medical air as well as to perform the specific calculations involved in its handling [11]. However, the author did not accomplish the computation of the mean consumption rates for standard operating conditions. Lara (2010) carried out a technical analysis of the gas distribution facilities in a 120-bed hospital in Ecuador [12], but individual gas consumption rates were not accounted for.

In a technical survey involving the buildings in Mexico DF devoted to health assistance activities, $62 \%$ of the sample buildings were seen to use oxygen in bulk. Also, the oxygen monthly consumption rate was observed to be lower than $1500 \mathrm{~m}^{3}$ for $61 \%$ of the buildings, greater than $3000 \mathrm{~m}^{3}$ for large buildings (28\%) and in the range $1500-3000 \mathrm{~m}^{3}$ for medium sized health centres (11\%) [13].

The French Red Cross (2006) edited a reference standards handbook to design a hospital, but they did not give any information about average medical gases consumption [14].

In Italy, Ciarapica et al. (2008) analysed medical gas installations in hospitals, but did not attempt to quantify neither the consumption rates nor the economic impact on management [15]. In Spain, García Sanz-Calcedo et al. (2017) reported on a quantitative analysis of the impact of maintenance management regarding energy consumption in hospitals, although the specific analysis of the impact due to the use of medical gases was not accomplished [16]. Medical gas annual consumption rates per patient in the Spanish hospital Virgen de las Nieves (located in Granada) are reported as $2.5 \mathrm{~m}^{3}$ oxygen, $0.03 \mathrm{~kg}$ nitrogen protoxide, $1 \mathrm{~m}^{3}$ nitrogen and $0.007 \mathrm{~m}^{3}$ medical air, according to the corresponding Eco-Management and Audit Scheme (EMAS) [17].

Gómez (2016) designed a protocol to optimise management actions regarding different typologies of medicinal gases and vacuum distribution subsystems, whose availability in a public hospital was assessed via multicriteria technique with Markov chains in repairable systems [18].

The appropriate caudal dose requirements of medical gases are currently provided by a variety of technical guides and manuals [19]. For instance, the British normative suggests a ratio of $20 \mathrm{~L}$ per minute, whereas the National Fire Protection Association (NFPA) sets 2 cubic feet per hour [20]. However, none of these technical guides includes neither the global consumption rates in a hospital nor specific criteria for consumption monitoring and control.

World Health Organization shows a growing concern for the high consumption of resources and impacts on global changes to climate and the environment of healthcare organizations [21]. These organizations must adequately manage economic and environmental impact of all their activities 
as a basic strategy for achieving sustainable development [22]. UN Sustainable Development Goals and their connection with sustainable healthcare, as the management of healthcare activities also affect populations' health [23].

The use of medicinal gases in hospitals generates a high environmental risk and inadequate management, especially in the case of the gases involving generation of NOx compounds, which can cause damage due to environmental emissions, excessive consumption, uncontrolled leaks or inadequate maintenance.

Efforts should therefore be focused on the appropriate monitoring and management of the facilities in order to achieve cost savings as well as to reduce atmospheric emissions [24]. Note that this is particularly relevant for the case of gases used as inhaled anaesthetic agents [25].

No specific indicators to monitor the actual mean consumption rates of medical gases in hospitals have been set so far. Furthermore, no detailed studies to assess the savings achieved by appropriate management actions have been reported. The mean consumption rates in a particular hospital might help identify leaks and misuses, like for instance intakes which are left open after surgeries in operating theatres.

The present work is aimed at determining the actual consumption rates of medical gases in hospitals in order to set suitable indicators to promote the appropriate design, control, management and optimisation of the involved facilities. The economic and maintenance costs of medical gas installations are also analysed. This type of research studies needs to be accomplished for the achievement of a sustainable healthcare model, given that the specific tools it provides are devoted to assessing a variety of design alternatives which will definitely improve general management in hospitals [26].

\section{Materials and Methods}

The present study reports on an analysis accounting for 12 Spanish hospitals in the period 2008-2016, which had been either built or fully renovated between 1990 and 2012. The useful floor area and the number of beds for all buildings under study met the intervals $2314-23,300 \mathrm{~m}^{2}$ and 20-194 beds. The mean annual consumption rates of medical gases were assessed as a function of the specific medical gas, the type of transport container and the supply method. In particular, the following medical gases were accounted for: Oxygen, nitrogen, medicinal air, carbon dioxide and nitrogen protoxide. The consumption of other anaesthetic gases such as halothane, enflurane, isoflurane, isoflurane, sevoflurane and desflurane was minimal, and was therefore not taken into account in this study. All carbon dioxide was used for laparoscopy interventions in minimally invasive surgeries.

Note that the amount of medical gas was expressed as the volume occupied by the gas at the moment it was inhaled by the patient, temperature and pressure assumed as $25{ }^{\circ} \mathrm{C}$ and $101.32 \mathrm{kPa}$ respectively. Table 1 shows the conversion factors used to bring supply conditions into usage conditions [27].

Table 1. Conversion factors.

\begin{tabular}{cccccc}
\hline Unit/Type of Gas & Oxygen & Medical Air & Nitrogen & Nitrogen Protoxide & Carbon Dioxide \\
\hline Gas volume $\left(\mathrm{m}^{3}\right)$ & 1 & 1 & 1 & 1 & 1 \\
Mass $(\mathrm{kg})$ & 1.342 & 1.2257 & 1.1874 & 1.847 & 1.874 \\
Liquid volume $(\mathrm{L})$ & 1.175 & 1.402 & 1.469 & 1.511 & 2.363 \\
Liquid density $(\mathrm{kg} / \mathrm{L})$ & 1.142 & 0.874 & 0.808 & 1.222 & 0.793 \\
Gas density $\left(\mathrm{kg} / \mathrm{m}^{3}\right)$ & 1.342 & 1.2257 & 1.1874 & 1.847 & 1.874 \\
\hline
\end{tabular}

For calculation purposes, a 50-L cylinder (B50) is computed to contain $10.60 \mathrm{~m}^{3}$ oxygen, $20.01 \mathrm{~m}^{3}$ carbon dioxide, $9.40 \mathrm{~m}^{3}$ nitrogen, $20.30 \mathrm{~m}^{3}$ nitrogen protoxide and $9.90 \mathrm{~m}^{3}$ medicinal air. A 10-L cylinder (B10) would accordingly contain $2.12 \mathrm{~m}^{3}$ oxygen, $4 \mathrm{~m}^{3}$ carbon dioxide, $1.88 \mathrm{~m}^{3}$ nitrogen, $4.06 \mathrm{~m}^{3}$ nitrogen protoxide and $1.98 \mathrm{~m}^{3}$ medicinal air. Finally, for 5 -L cylinder (B5) the equivalent 
volumes are $1.06 \mathrm{~m}^{3}$ oxygen, $2 \mathrm{~m}^{3}$ carbon dioxide, $0.94 \mathrm{~m}^{3}$ nitrogen, $2.03 \mathrm{~m}^{3}$ nitrogen protoxide and $0.99 \mathrm{~m}^{3}$ medicinal air.

For those hospitals where medicinal air is produced using an oxygen-nitrogen mixer the mean consumption rates were straightforwardly computed from those of nitrogen, just by accounting for the composition of medicinal air as $21 \%$ oxygen and $79 \%$ nitrogen [28]. Moreover, the portion of the oxygen volumes devoted for direct use by inhalation (thus not for medical air production) was set in advance.

On another note, the following categories were accounted for the hospital staff: Physicians, nurses, nursing assistants, administrative staff, cleaning staff, maintenance staff, orderlies, cafeteria staff, cooking staff and pharmacy staff among others [29]. All information in this topic had been checked and supervised by the economic-financial department at each of the target hospitals. The selected variables relating to the healthcare actions under study were the number of: Annual hospitalisation stays, hospital surgeries, outpatient surgeries, hospital discharges, endoscopies, births and emergency actions. Interviews and focus groups to select the variables were conducted. As for the case of the information regarding the staff categories, all the evidence relating to the abovementioned variables had properly been supervised by the medical-care management department at each hospital.

Information regarding costs was provided by the hospitals' accounting departments from invoice records between 2008 and 2017, which was matched to that from the corresponding medical gas supplying companies.

Medical gas patterns were assessed after previous meetings with the hospital's maintenance engineers, in which the following topics had been accounted for: Analysis of existing records, monitoring of patients', visitors' and staff's habits, measurement of gas flow rates and individual surveys on medical gas usage.

In the course of the research, relationships between medical gas consumption and other functional and operational parameters from each hospital were identified, including the year of construction, useful surface area, number of users, number of workers, and number of beds, among others.

For each of the target hospitals, the useful floor area was taken to be that of the outer perimeter of a covered space, subtracting the constructive elements related to the building's closures, partitions, structure and installations [30]. Both the built and useful floor areas of the hospitals under study were obtained from the corresponding construction projects. Table 2 shows the variables used for the study.

Table 2. Variables used for the study.

\begin{tabular}{ccl}
\hline Variable & Abb. & Definition \\
\hline $\mathrm{N}^{\circ}$ beds & $\mathrm{B}$ & Number of operational beds in a given hospital \\
\hline Useful floor area & $\mathrm{S}$ & $\begin{array}{l}\text { Outer perimeter of a covered space, subtracting the constructive elements } \\
\text { related to the building's closures, partitions, structure and installations. }\end{array}$ \\
\hline $\mathrm{N}^{\circ}$ workers & $\mathrm{W}$ & Usual number of hospital workers per year \\
\hline $\mathrm{N}^{\circ}$ hospital discharges & $\mathrm{Dc}$ & $\begin{array}{l}\text { The expiration of a healthcare episode (either due to recovery, death or transfer) } \\
\text { treated in the hospitalization area or the surgical day hospital. }\end{array}$ \\
\hline $\begin{array}{c}\mathrm{N}^{\circ} \text { surgeries with } \\
\text { hospitalization }\end{array}$ & $\mathrm{Sg}$ & Annual number of inpatient surgeries \\
\hline $\mathrm{N}^{\circ}$ hospital stays & $\mathrm{St}$ & A period no shorter than overnight-lunch or overnight-dinner \\
\hline $\begin{array}{c}\mathrm{N}^{\circ} \text { emergency } \\
\text { interventions }\end{array}$ & Em & Annual number of patients seen in emergency care
\end{tabular}

To compare different types of medical gas supply in a hospital from an economic perspective, a cost-effectiveness analysis (CEA) was performed. The maintenance costs and security system were used as a measure of effectiveness in this analysis.

The potential correlations among all the aforementioned variables were assessed, taking Pearson's correlation coefficient as the parameter to scan the linear dependence between two random quantitative variables -for any measuring scale of the variables-, and avoiding untypical values (outliers). 
Statistical correlation techniques to estimate the relationships between the variables were applied. The conditional expectation of each dependent variable given the independent variables was also analysed. Pearson's correlation was used as it was proven that there was a linear relationship between the continuous variables [31].

To detect outliers, outliers were considered to be all those outside the range $\mu \pm 3 \sigma$, with $\mu$ being the average annual consumption of a medicinal gas and $\sigma$ its standard deviation [32].

Finally, the available data records were used to perform a detailed statistical study via Analysis of Variance (ANOVA) [33]. The normality of the sample was checked by applying the Shapiro-Wilk test, calculating the mean and the sample variance [34]. The Levene test was performed to evaluate the equality of the variances for the sample variables; given the existence of these significant differences, an analysis of multiple comparisons (post hoc test) was carried out through the Fisher test, with the aim of analysing the existing differences exhaustively [35].

\section{Results}

The results achieved from the abovementioned methodology are reported along the present section.

\subsection{Correlation between Average Annual Medical Gas Consumption and Useful Floor Area}

Figure 1 depicts the dependence of medical gas consumption on useful floor area for the set of hospitals under study. The two variables are observed to show a high correlation $\left(R^{2}=0.7937\right)$ and to meet the following analytical expression:

$$
C_{O}=0.0002 S^{1.3126}
$$

where $C_{O}$ and $S$ stand for the average annual consumption of oxygen and for the useful floor area, expressed in $\mathrm{Dm}^{3}$ and $\mathrm{m}^{2}$ respectively. Such an expression is suitable to size new oxygen installations and might serve as a reference for the monitoring of oxygen consumption in hospitals under standard operating and maintenance conditions.

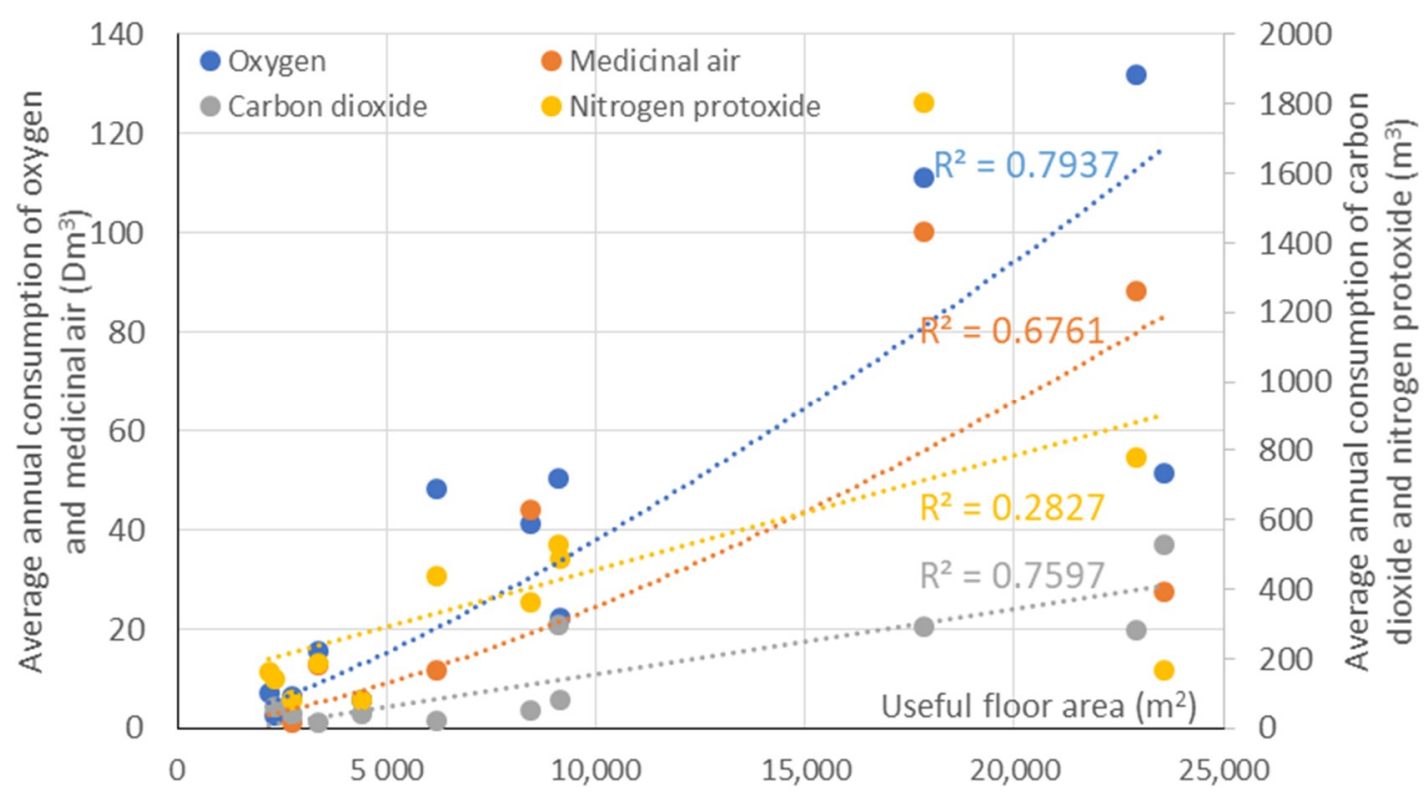

Figure 1. Medical gas consumption as a function of the useful floor area for the set of hospitals under study. 
No correlations were achieved between the useful floor area and medicinal air consumption, carbon dioxide consumption or nitrogen protoxide consumption $\left(R^{2}=0.6761, R^{2}=0.7597\right.$, $R^{2}=0.2827$, respectively).

\subsection{Correlation between Average Annual Medical Gas Consumption and Number of Beds}

Figure 2 illustrates the dependence of medical gas consumption on the number of beds in the hospitals under study for standard operating and maintenance conditions.

The number of hospital beds was observed to be highly correlated to the consumption of both oxygen and medicinal air $\left(R^{2}=0.9551, R^{2}=0.8271\right)$ according to the following expressions:

$$
\begin{gathered}
C_{O}=0.0083 B^{1.8140} \\
C_{M A}=0.0003 B^{2.4303}
\end{gathered}
$$

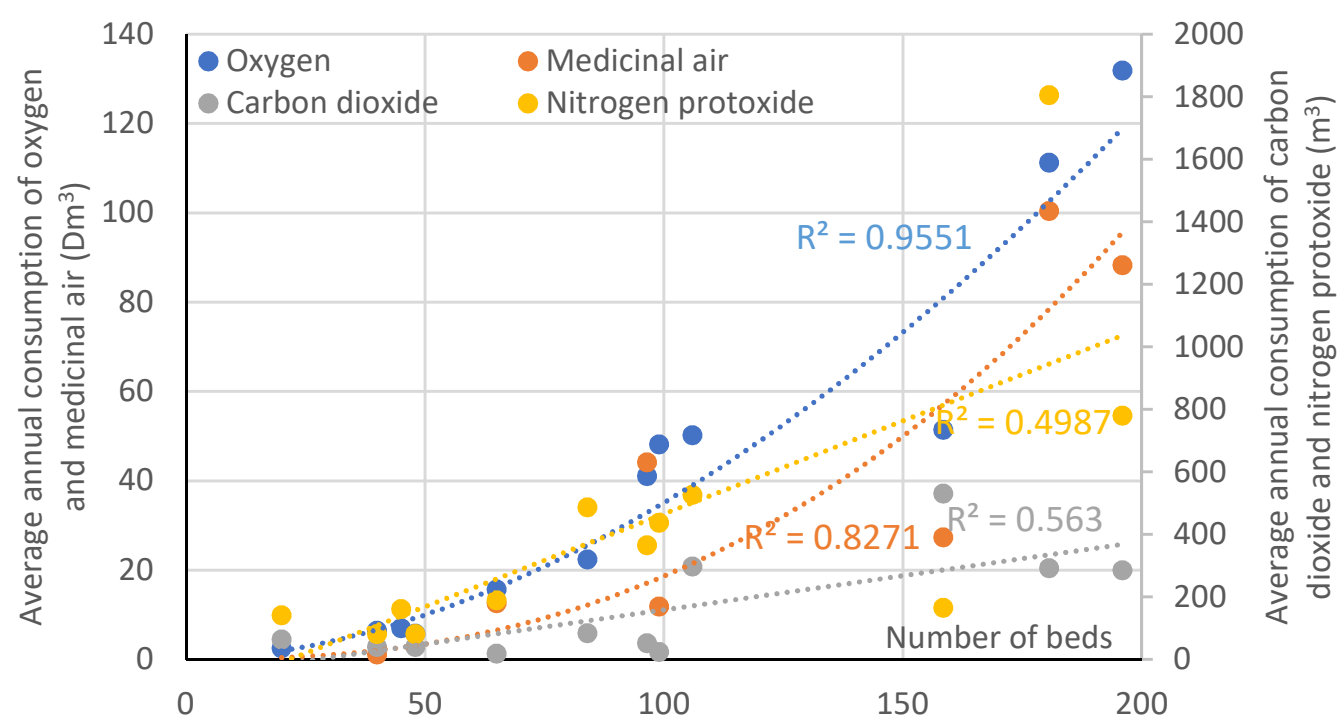

Figure 2. Medical gas consumption as a function of the number of beds for the set of hospitals under study.

$C_{M A}$ and $B$ represent the average annual consumption of medicinal air expressed in Dm3 and the number of hospital beds, respectively. Again, the expressions are therefore suitable to size new installations and might serve as a reference for monitoring of the consumption of those medical gases.

No statistical correlation was achieved between the number of beds and the consumption of carbon dioxide or nitrogen protoxide $\left(R^{2}=0.5630\right.$ and $R^{2}=0.4987$, respectively).

\subsection{Correlation between Average Annual Medical Gas Consumption and Number of Workers}

The statistical correlation between medical gas consumption and the number of workers $(W)$ is depicted in Figure 3 and in expressions (4) and (5).

$$
\begin{gathered}
C_{O}=20.57 W-16.284 \\
C_{M A}=0.0003 W^{1.9625}
\end{gathered}
$$

Oxygen and medicinal air consumption rates were seen to be highly correlated to the number of workers $\left(R^{2}=0.9161\right.$ and $\left.R^{2}=0.8213\right)$, but no correlation was achieved for carbon dioxide or nitrogen protoxide $\left(R^{2}=0.5617, R^{2}=0.6771\right)$. 


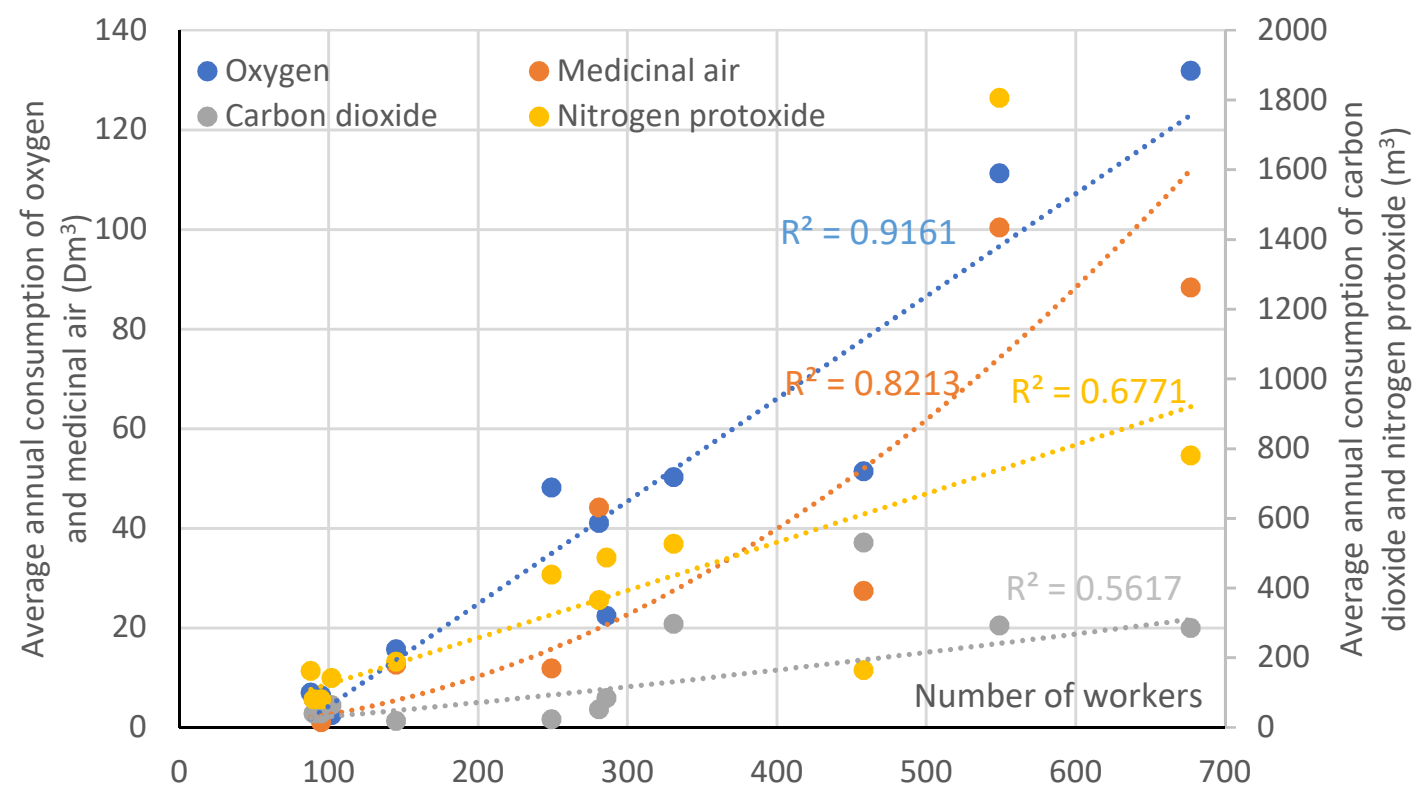

Figure 3. Medical gas consumption as a function of the number of workers for the set of hospitals under study.

\subsection{Correlations between Average Annual Medical Gas Consumption and Healthcare Activity}

As a first step, the number of annual discharges $(D c)$ was analysed for each of the target hospitals, i.e., the expiration of a healthcare episode (either due to recovery, death or transfer) treated in the hospitalisation area or the surgical day hospital. As can be observed in Figure 4 together with Equations (6) and (7), this variable was seen to be correlated to the consumption rates of oxygen and medicinal air $\left(R^{2}=0.9476\right.$ and $R^{2}=0.9515$, respectively). In contrast, no correlation was achieved for carbon dioxide or nitrogen protoxide $\left(R^{2}=0.4127, R^{2}=0.5984\right)$.

$$
\begin{gathered}
C_{O}=0.0003 D c^{1.3467} \\
C_{M A}=0.010 D c-36.1470
\end{gathered}
$$

The correlations between the number of surgeries with hospitalisation $(S g)$ and the medical gas consumption rates were then analysed for each of the target hospitals (see Figure 5). As a result, the number or surgeries with hospitalisation was found to be correlated to medicinal air consumption $\left(R^{2}=0.9889\right)$ as in the following expression:

$$
C_{M A}=0.0184 S g-25.566
$$

No statistical correlations were evidenced between the annual number of hospital discharges and oxygen consumption $\left(R^{2}=0.5719\right)$, carbon dioxide consumption $\left(R^{2}=0.2709\right)$ or nitrogen protoxide consumption $\left(\mathrm{R}^{2}=0.5577\right)$. 


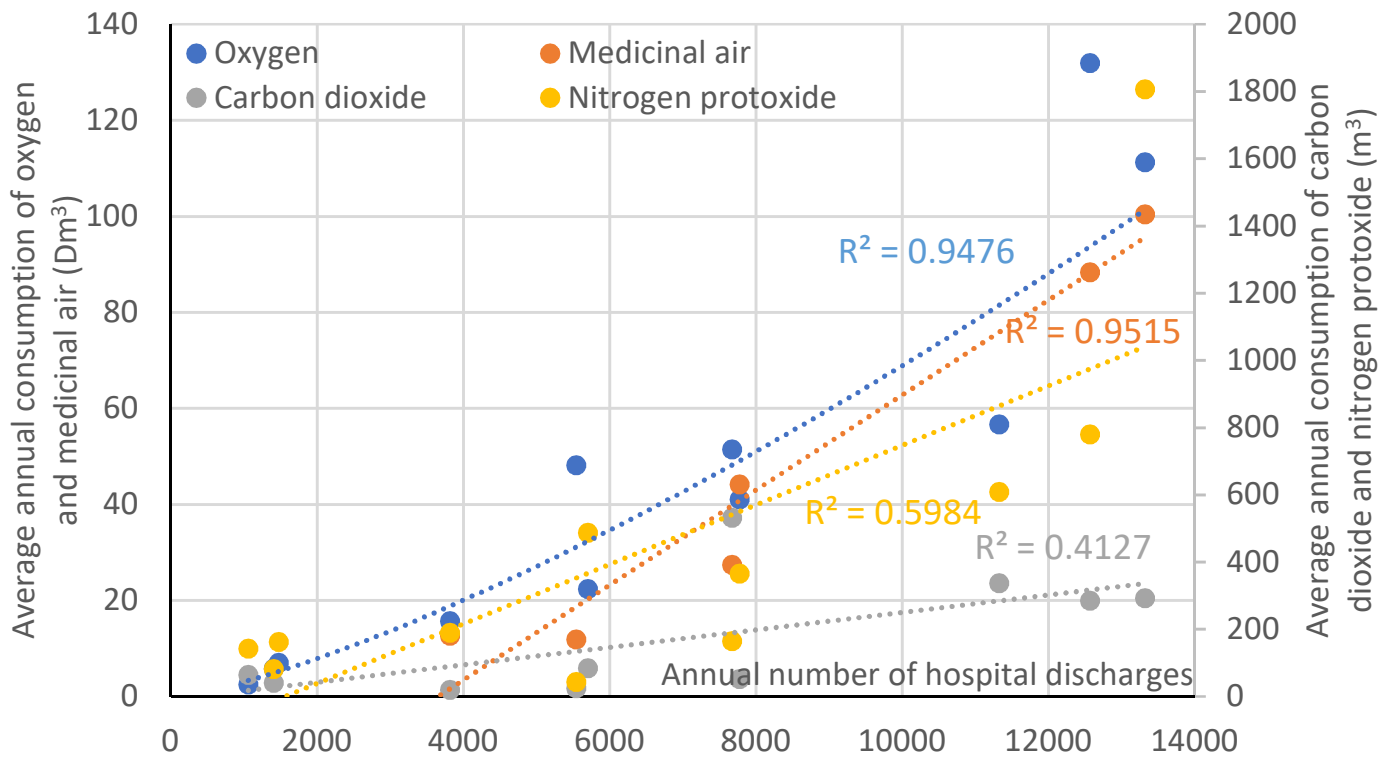

Figure 4. Medical gas consumption as a function of the number of annual hospital discharges for the set of hospitals under study.

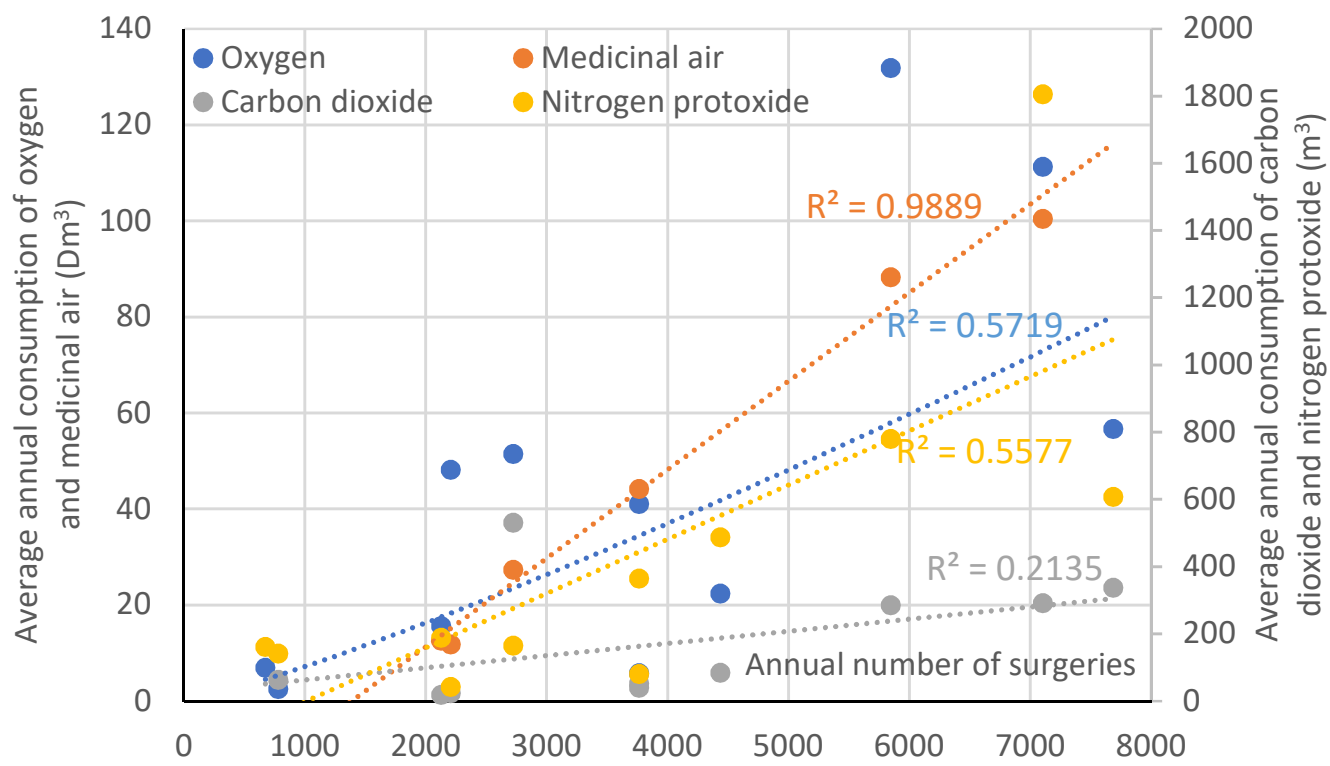

Figure 5. Medical gas consumption as a function of the number of annual surgeries for the set of hospitals under study.

The potential correlations between the annual number of hospitalisation stays ( $S t$, defined as a period no shorter than overnight-lunch or overnight-dinner) and the medical gas consumption rates had also been accounted for (see Figure 6). A very strong correlation $\left(R^{2}=0.9961\right)$ was evidenced for the particular case of oxygen consumption, and the corresponding data were fitted to the analytical expression given in Equation (9). 


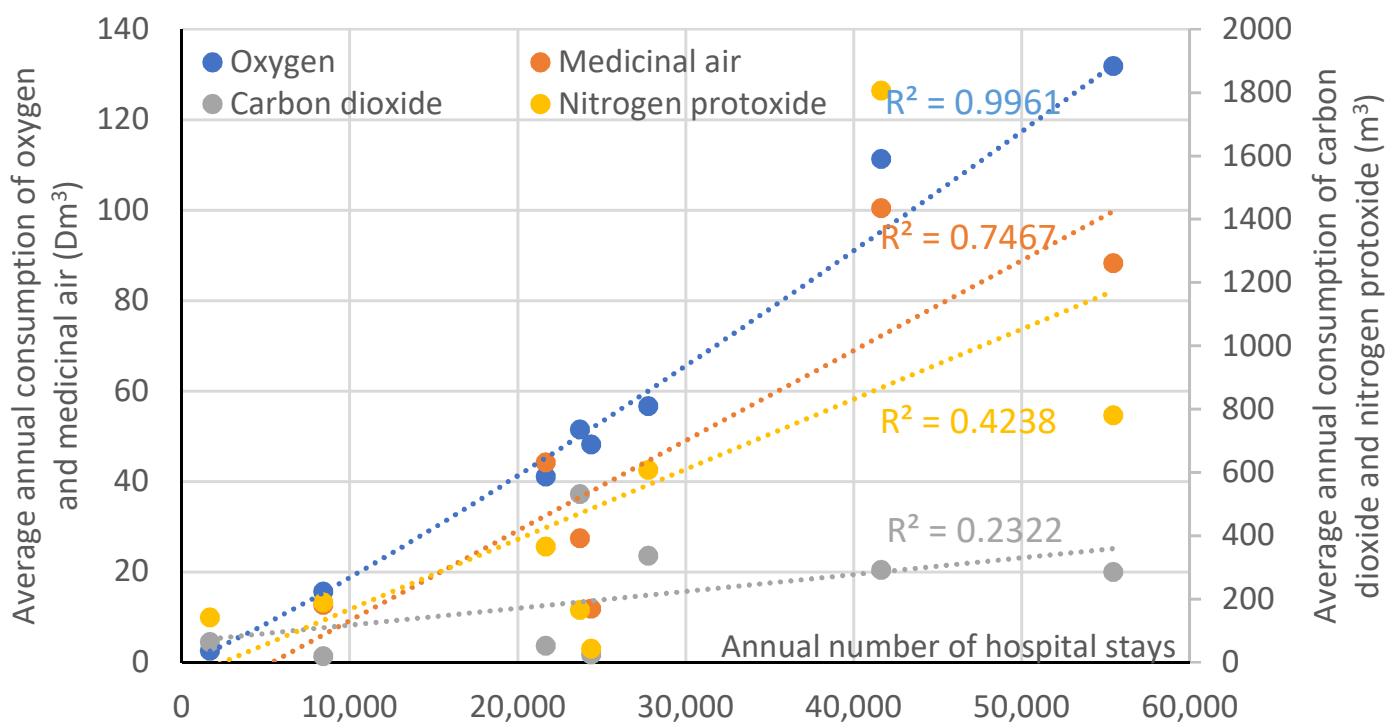

Figure 6. Medical gas consumption as a function of the number of annual hospital stays for the set of hospitals under study.

$$
C_{O}=0.0005 S t^{1.1415}
$$

No correlations were evidenced between the number of hospital stays and the rest of the medical gases under study, namely medicinal air, carbon dioxide and nitrogen protoxide (correlation indexes $R^{2}=0.7467, R^{2}=0.2322$ and $R^{2}=0.4238$, respectively).

With regard to the annual number of endoscopies (Es) as related to medical gas consumption (Figure 7), no correlations were found except for the case of oxygen (correlation index $R^{2}=0.9309$ and analytical fit as in Equation (10)).

$$
C_{O}=0.0151 E s-2.6197
$$

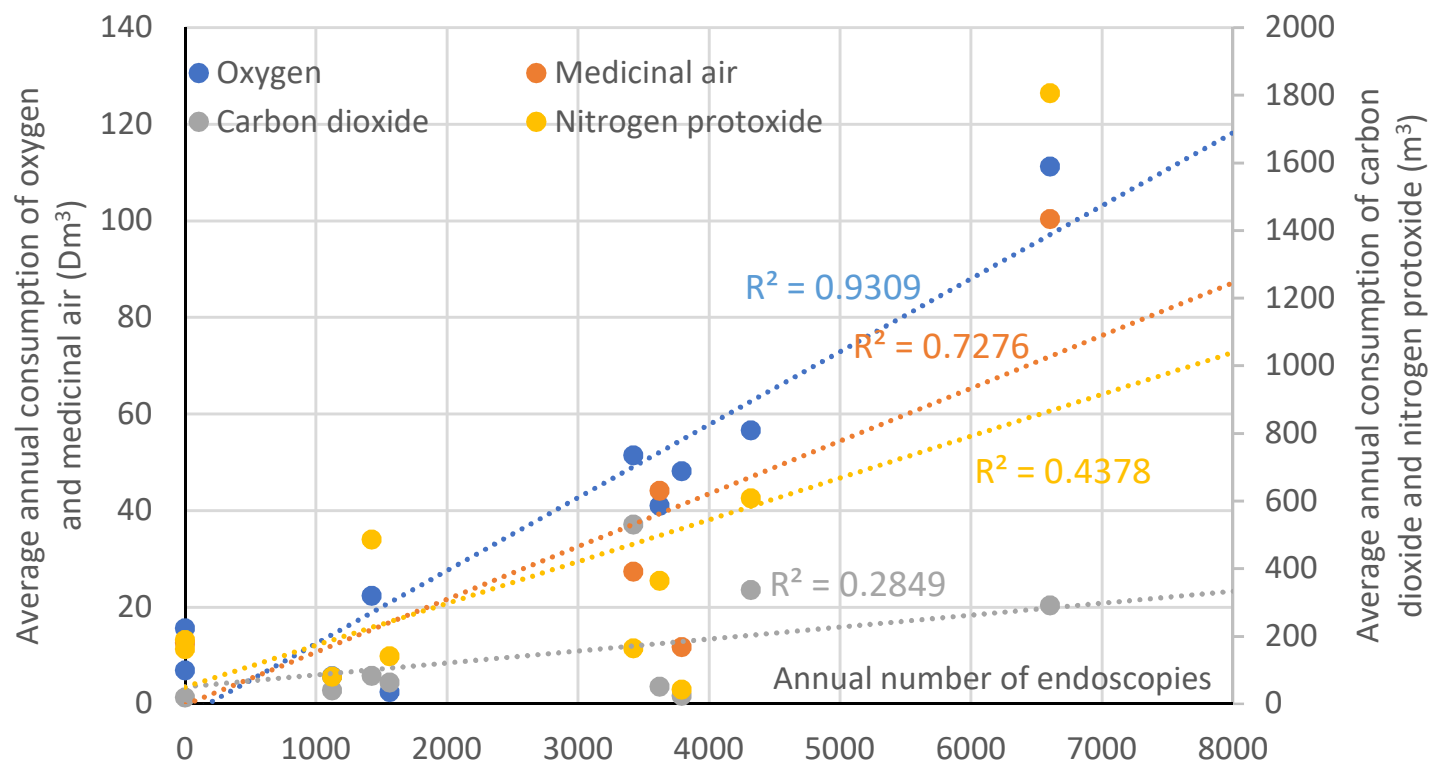

Figure 7. Medical gas consumption as a function of the annual number of endoscopies for the set of hospitals under study. 
The potential correlation between the medical gas consumption rates and the number of laboratory tests carried out in the set of hospitals was also assessed. However, no correlation evidence was found for the cases of medicinal air $\left(R^{2}=0.5915\right)$, carbon dioxide $\left(R^{2}=0.3261\right)$ or nitrogen protoxide $\left(R^{2}=0.2713\right)$. A high correlation $\left(R^{2}=0.9010\right)$ between oxygen consumption and number of laboratory tests carried out (Lt) was founded. The results are showed in Figure 8 and Equation (11):

$$
C_{O}=0.00008 L t+9.4312
$$

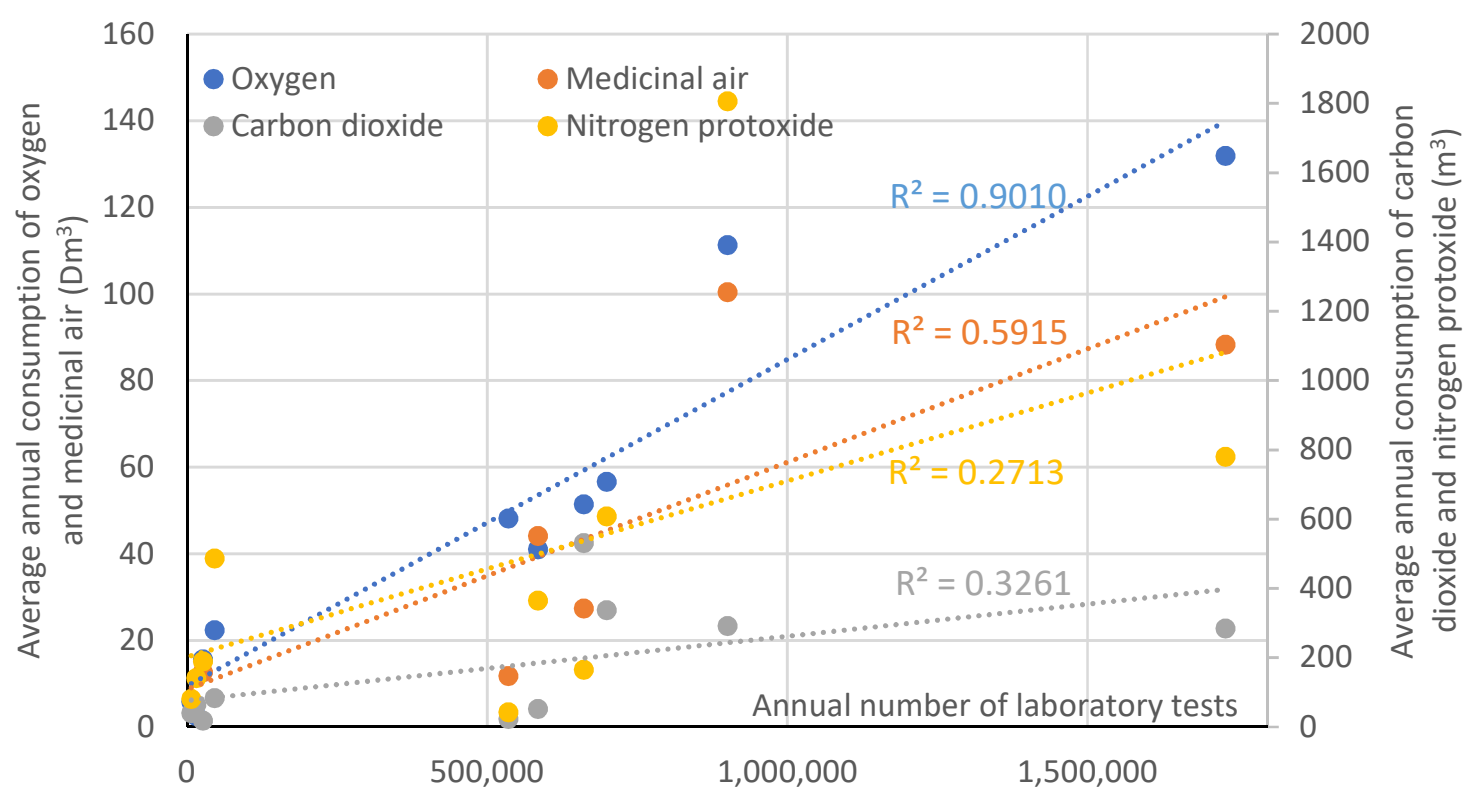

Figure 8. Medical gas consumption as a function of the annual number of laboratory tests for the set of hospitals under study.

It should finally be noted that correlations between medical gas consumption and each of the rest of the involved healthcare variables were also assessed (i.e., number of births, number or emergency actions and number of outpatient surgeries). However, no acceptable values for Pearson's coefficient were achieved and potential interdependence was therefore rejected.

\subsection{Analysis of the Impact of Medical Gas Installations on Hospital Maintenance}

Given that maintenance management is well-known to influence energy consumption in hospitals [16], the workload associated to medical gas installations as compared to that of the global maintenance of the building was estimated [36]. For such purposes, the maintenance records of the hospitals under study were analysed within the period 2012-2016. As a result, 384,124 actions were accounted for, 172,990 of which were labelled as corrective ones-in particular 12,773 (7.38\%) were related to medical gas installations-.

On another note, with regard to preventive actions, a total of 211,134 were accounted for and sorted into the three following groups: (i) 64,596 room revisions, 4037 (6.25\%) of which involved medical gas interventions; (ii) 85,175 protocols, 18,882 (22.17\%) of which involved medical gas interventions; (iii) 61,363 preventive revisions, $14,418(23.50 \%)$ of which involved medical gas interventions. This yields a total of 50,110 interventions involving medical gas installations (i.e., $13.05 \%$ of the total number of technical interventions) sorted as 12,773 corrective and 37,337 preventive (i.e., $7.38 \%$ and $17.68 \%$ of the total number of corrective and preventive actions, respectively).

Table 3 lists the average annual number of hours devoted to medical gas installations, as well as the associated costs. The annual costs derived from interventions by external companies reached 
$6948 €$. Maintenance interventions in the ambit of medical gases were carried out by specialised hospital staff and involved $1944 \mathrm{~h}$-workload with total annual costs quantified as $25,822 €$.

Table 3. Annual maintenance interventions relating medical gas installations.

\begin{tabular}{ccccc}
\hline Type of Maintenance Intervention & $\begin{array}{c}\text { \% Over Total } \\
\text { Installations }\end{array}$ & $\begin{array}{c}\text { Average Annual } \\
\text { Number of } \\
\text { Interventions }\end{array}$ & $\begin{array}{c}\text { Annual Number } \\
\text { of Hours }\end{array}$ & $\begin{array}{c}\text { Annual } \\
\text { Costs (€) }\end{array}$ \\
\hline Total corrective & 3.33 & 511 & 756 & 12,094 \\
Room revisions (preventive) & 1.05 & 161 & 70 & 983 \\
Protocols (preventive) & 4.92 & 755 & 448 & 5371 \\
Preventive revisions (preventive) & 3.75 & 577 & 670 & 7374 \\
\hline
\end{tabular}

\subsection{Cost Analysis}

Medicinal air show different prices depending on whether it is supplied in pressure cylinders or is produced in situ by mixing oxygen and nitrogen in specific hospital facilities [37]. For hospitals involving high consumption rates, the medical gas supplier usually assumes the costs associated with the supply, installation and renting of cryogenic tanks. However, this option is subject to the existence of an appropriate location for storing gas tanks and a safe and suitable access for the tanker truck. For the particular case of pressure cylinders, some suppliers use to charge a monthly rental. On the other hand, gas supply by tankers sometimes involves a specific discharge fee.

Figure 9 depicts the mean acquisition price-as referred to 2017-for each of the medical gases involved in the present study. As can be observed, the price corresponding to B10 cylinders rockets up to about an 80-fold value for nitrogen. Carbon dioxide doubles its price if supplied as B10 cylinders, and costs would still be higher if it were supplied in B5 cylinders. On another note, the costs associated to consumption of medicinal air produced in situ by a mixer are almost one fourth of those arising from purchase of B50 cylinders.

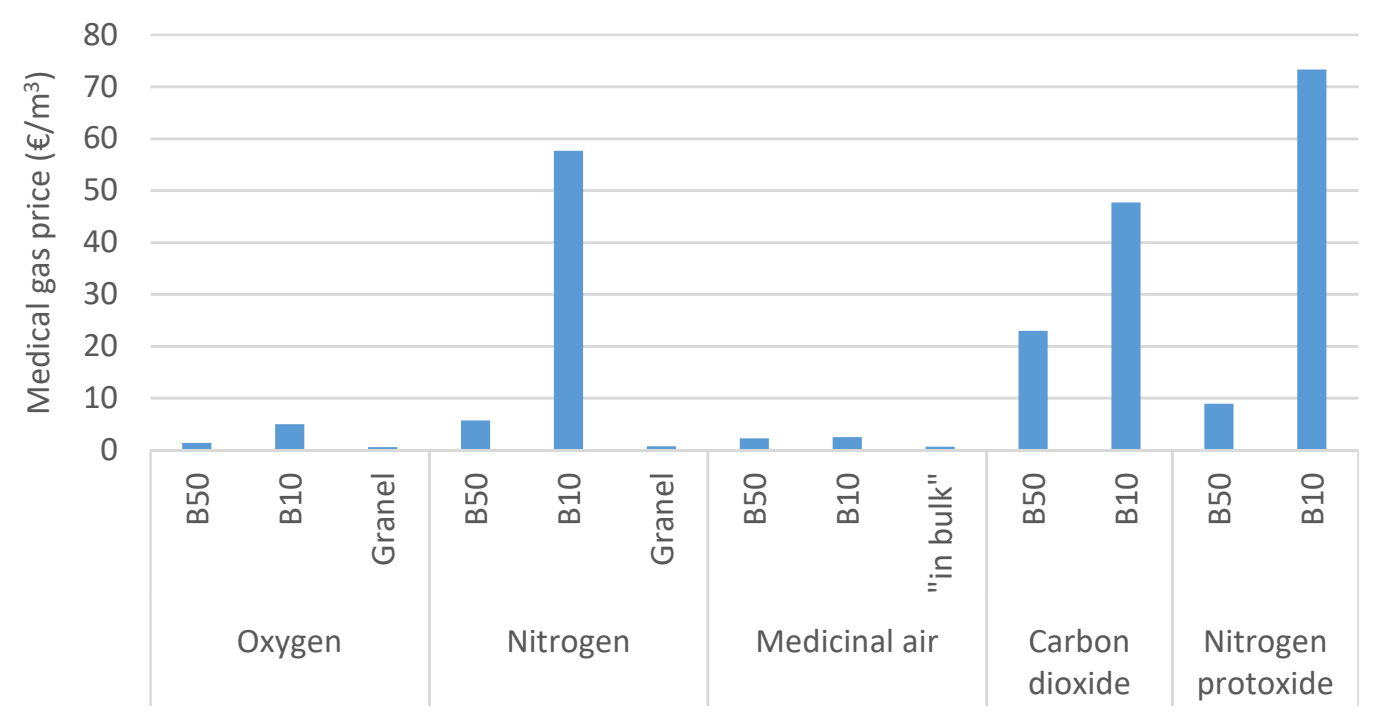

Figure 9. Medical gas price per unit volume $\left(25^{\circ} \mathrm{C}, 101.32 \mathrm{kPa}\right)$ for different supplying format.

The carbon dioxide consumed in laparoscopic surgeries is usually supplied by B10 cylinders directly attached to the laparoscopic tower. However, it could also have been supplied by wall gas outlets in the operating room, directly connected to B50 cylinders. The mean annual cost for the period 2015-2016 was estimated for four of the hospitals under study, together with the potential costs that would have been achieved if carbon dioxide had been fully supplied by B50 cylinders. As a result, 
potential annual savings were quantified as $7000 €, 3000 €$ and $1500 €$ for Montepríncipe, Sanchinarro and HM Modelo Hospitals, respectively.

The percentage distribution of medical gas costs between 2008 and 2017 was computed as $47 \%$ for oxygen, $27 \%$ for nitrogen, $11 \%$ for medicinal air, $9 \%$ for carbon dioxide and $6 \%$ for nitrogen protoxide. It should be noted that most nitrogen consumption, as well as part of the oxygen volumes consumed, were associated with the production of medicinal air. The mean annual cost for 2017 arising from medical gas supply in a hospital was estimated as $70,000 €$.

\subsection{Statistical Analysis}

The statistical study hereby reported was based on the statistical analysis of the variance (ANOVA). The null hypothesis states that there is no difference or association between variables of interest, so that all means for the population are equal for all conditions. In order to seek statistical significance for mean differences, the $p$-value was compared to the significance level $(0.05)$ to test the null hypothesis, so that if the $p$-value is less than or equal to the significance level (i.e., $p$-value $\leq 0.05$ ) then the null hypothesis could be rejected and it could be concluded that not all population means are equal. Otherwise, the $p$-value being greater than the significance level would prove there is not enough evidence to reject the null hypothesis. Table 4 shows the results for the $p$-value corresponding to the ANOVA for the average annual medical gas consumption for a 0.05 level of significance.

Table 4. Results for the $p$ corresponding to the ANOVA for the average annual medical gas consumption for a 0.05 level of significance.

\begin{tabular}{cccccccc}
\hline $\begin{array}{c}\text { Consumption } \\
\text { Ratios }\end{array}$ & $\begin{array}{c}\text { Hospital } \\
\text { Discharges }\end{array}$ & $\begin{array}{c}\text { Hospital } \\
\text { Surgeries }\end{array}$ & $\begin{array}{c}\text { Outpatient } \\
\text { Surgeries }\end{array}$ & $\begin{array}{c}\text { Number } \\
\text { Endoscopies }\end{array}$ & $\begin{array}{c}\text { Laboratory } \\
\text { Tests }\end{array}$ & $\begin{array}{c}\text { Emergency } \\
\text { Actions }\end{array}$ & $\begin{array}{c}\text { Hospitalisation } \\
\text { Stays }\end{array}$ \\
\hline$\frac{m^{3} \text { oxygen }}{n \text { number of beds }}$ & $0.045^{*}$ & 0.182 & 0.175 & 0.453 & 0.065 & $0.049 *$ & $0.028^{*}$ \\
$\frac{m^{3} \text { oxygen }}{\text { useful floor area }}$ & 0.183 & 0.472 & 0.331 & 0.401 & 0.549 & 0.357 & $0.048^{*}$ \\
$\frac{m^{3} \text { oxygen }}{\text { hospital discharges }}$ & $0.041^{*}$ & 0.095 & 0.197 & 0.315 & 0.367 & 0.574 & $0.046 *$ \\
$\frac{m^{3} \text { oxygen }}{\text { hospital stays }}$ & 0.052 & 0.247 & 0.674 & 0.571 & 0.247 & 0.387 & $0.02 *$ \\
$\frac{m^{3} \text { medicinal air }}{n \text { umber of beds }}$ & $0.039 *$ & 0.547 & 0372 & 0.148 & 0.261 & 0.102 & $0.042 *$ \\
$\frac{m^{3} \text { medicinal air }}{\text { useful floor area }}$ & 0.056 & 0.471 & 0.187 & 0.286 & 0.471 & 0.871 & $0.049 *$ \\
$\frac{m^{3} \text { medicinal air }}{\text { hospital stays }}$ & $0.02 *$ & 0.247 & 0.143 & 0.321 & 0.247 & 0.652 & $0.041 *$ \\
$\frac{m^{3} \text { carbon dioxide }}{\text { surgeries }}$ & 0.357 & $0.068^{*}$ & $0.049 *$ & $0.037 *$ & 0.741 & 0.648 & 0.341 \\
$\frac{m^{3} \text { nitrogen protoxide }}{\text { surgeries }}$ & 0.493 & $0.024 *$ & $0.039 *$ & $0.047 *$ & 0.735 & 0.598 & 0.281 \\
\hline
\end{tabular}

* At the 0.05 level, the population means are significantly different.

Out of the target hospitals, those with more than 90 beds were observed to show higher oxygen consumption rates per bed than hospitals with less than 90 beds $(p=0.0014)$ and hospitals with an annual number of discharges exceeding 6000 showed higher medicinal air consumption rates per discharge than the rest $(p=0.049)$. With regard to hospital stays, higher oxygen consumption rates per stay were achieved for hospitals with more than 24,000 annual stays than for those below such value $(p=0.048)$. Higher volumes of medicinal air were consumed at hospitals exceeding 3000 annual surgeries than at those which do not reach that number $(p=0.0215)$. On another note, hospitals accounting for more than 55,000 annual laboratory tests showed a higher oxygen consumption rate per test $(p=0.0343)$ and a lower nitrogen protoxide rate per test $(p=0.0073)$ than those with less than this threshold value. Finally, nitrogen protoxide consumption was evidenced to increase with the annual number of hospital surgeries $(p=0.042)$ and carbon dioxide consumption was accordingly seen to increase with the number of outpatient surgeries $(p=0.038)$. 


\subsection{Healthcare Indicators}

As reference indicators, Table 5 lists the percentiles (15\%,50\% and 85\%), the arithmetic means and the standard deviations associated with the various annual rates reported in the present work.

Table 5. Annual consumption rates and percentiles of medical gases as related to the various specific healthcare indicators.

\begin{tabular}{|c|c|c|c|c|c|c|}
\hline & Annual Rates ( $\mathrm{m}^{3}$ Gas Divided by...) & Mean & Deviation & $\mathbf{P} 15 \%$ & $\mathbf{P} 50 \%$ & P85\% \\
\hline \multirow{7}{*}{ Oxygen } & $\mathrm{N}^{\circ}$ beds $(\mathrm{B})$ & 348.26 & 182.29 & 124.65 & 324.77 & 628.72 \\
\hline & Useful floor area $(S)$ & 4.01 & 2.02 & 1.27 & 4.65 & 6.32 \\
\hline & $\mathrm{N}^{\circ}$ workers $(\mathrm{W})$ & 121.61 & 55.95 & 56.48 & 112.39 & 196.43 \\
\hline & $\mathrm{N}^{\circ}$ hospital discharges $(\mathrm{Dc})$ & 5.80 & 2.35 & 3.61 & 5.00 & 9.04 \\
\hline & $\mathrm{N}^{\circ}$ surgeries with hospitalisation $(\mathrm{Sg})$ & 11.35 & 7.05 & 2.88 & 10.40 & 21.98 \\
\hline & $\mathrm{N}^{\circ}$ hospital stays (St) & 2.06 & 0.33 & 1.62 & 2.01 & 2.57 \\
\hline & $\mathrm{N}^{\circ}$ emergency interventions (Em) & 1.08 & 0.58 & 0.44 & 0.87 & 1.80 \\
\hline \multirow{7}{*}{$\begin{array}{l}\text { Medicinal } \\
\quad \text { air }\end{array}$} & $\mathrm{N}^{\circ}$ beds $(\mathrm{B})$ & 325.97 & 168.51 & 122.15 & 324.80 & 550.95 \\
\hline & Useful floor area (S) & 3.54 & 1.56 & 1.22 & 3.77 & 5.37 \\
\hline & $\mathrm{N}^{\circ}$ workers $(\mathrm{W})$ & 110.86 & 49.87 & 48.12 & 108.79 & 181.74 \\
\hline & $\mathrm{N}^{\circ}$ hospital discharges (Dc) & 4.88 & 2.00 & 2.19 & 4.62 & 7.51 \\
\hline & $\mathrm{N}^{\circ}$ surgeries with hospitalisation $(\mathrm{Sg})$ & 10.39 & 3.73 & 5.39 & 10.90 & 15.06 \\
\hline & $\mathrm{N}^{\circ}$ hospital stays $(\mathrm{St})$ & 1.53 & 0.62 & 0.52 & 1.55 & 2.39 \\
\hline & $\mathrm{N}^{\circ}$ emergency interventions (Em) & 0.94 & 0.45 & 0.43 & 0.96 & 1.51 \\
\hline \multirow{7}{*}{$\begin{array}{l}\text { Carbon } \\
\text { dioxide }\end{array}$} & $\mathrm{N}^{\circ}$ beds $(\mathrm{B})$ & 3.044 & 2.092 & 0.553 & 2.961 & 6.443 \\
\hline & Useful floor area (S) & 0.029 & 0.017 & 0.010 & 0.027 & 0.056 \\
\hline & $\mathrm{N}^{\circ}$ workers $(\mathrm{W})$ & 0.986 & 0.632 & 0.239 & 0.915 & 1.844 \\
\hline & $\mathrm{N}^{\circ}$ hospital discharges $(\mathrm{Dc})$ & 0.056 & 0.045 & 0.010 & 0.043 & 0.128 \\
\hline & $\mathrm{N}^{\circ}$ surgeries with hospitalization $(\mathrm{Sg})$ & 0.094 & 0.101 & 0.021 & 0.060 & 0.240 \\
\hline & $\mathrm{N}^{\circ}$ hospital stays $(\mathrm{St})$ & 0.022 & 0.025 & 0.003 & 0.012 & 0.067 \\
\hline & $\mathrm{N}^{\circ}$ emergency interventions (Em) & 0.007 & 0.004 & 0.002 & 0.008 & 0.012 \\
\hline \multirow{7}{*}{$\begin{array}{l}\text { Nitrogen } \\
\text { protoxide }\end{array}$} & $\mathrm{N}^{\circ}$ beds $(\mathrm{B})$ & 8.924 & 4.884 & 2.702 & 7.800 & 15.483 \\
\hline & Useful floor area (S) & 0.099 & 0.052 & 0.027 & 0.101 & 0.177 \\
\hline & $\mathrm{N}^{\circ}$ workers $(\mathrm{W})$ & 2.909 & 1.465 & 1.315 & 2.496 & 5.219 \\
\hline & $\mathrm{N}^{\circ}$ hospital discharges (Dc) & 0.142 & 0.065 & 0.070 & 0.130 & 0.249 \\
\hline & $\mathrm{N}^{\circ}$ surgeries with hospitalisation (Sg) & 0.238 & 0.121 & 0.086 & 0.225 & 0.403 \\
\hline & $\mathrm{N}^{\circ}$ hospital stays (St) & 0.057 & 0.043 & 0.017 & 0.037 & 0.129 \\
\hline & $\mathrm{N}^{\circ}$ emergency interventions (Em) & 0.024 & 0.013 & 0.007 & 0.025 & 0.044 \\
\hline
\end{tabular}

\section{Discussion}

The annual consumption of medicinal gases in hospitals being correlated with levels of medical activity [38] was proven, which it was to be expected as they are used exclusively for patient treatment. Therefore, increases in the level of activity in a hospital proportionally increases medicinal gases consumption. In particular, the increase in surgical activity increases the consumption of nitrogen protoxide, the number of outpatient surgeries increases the consumption of carbon dioxide and the increase in the number of stays increases the consumption of oxygen and medical air.

The exhaustive monitoring of mean consumption rates of medical gases would definitely help to identify potential failures or gas leaks in the associated facilities [39]. The technical responsibility regarding medical gas equipment in hospitals lies both in the maintenance and in the hospital pharmacy departments [40]. It should be noted that safe medical gas installations are absolutely critical, since any failure might result in a high clinic risk episode for patients [41]. For this reason, leaky gas valves should be replaced and frequent maintenance inspections on medical gas facilities should also occur [42]. In addition, technical staff should be appropriately trained in the handling of flowmeters and of the specific equipment involved in medical gas installations [43].

Research in this field to date has been thin. There are only references to studies focusing on very small samples, with little or no statistical significance when analysing a single hospital and a single type of medicinal gas. The lack of reliable data on the average consumption of medical gases used in a hospital prevents managers from identifying their reference consumption. 
Whenever the consumption rates are evidenced to be sufficiently high, the installation of cryogenic tanks supplied by tanker trucks should be regarded as an efficient cost-saving strategy [44]. A further potential measure to promote cost savings is the installation of specific devices to interrupt the operation of anaesthetic evacuation system (AES) inlets, which are designed to operate when the respirator is not in use, and which show a consumption rate ranging 50 to $90 \mathrm{~L}$ per minute of propellant gas-typically medicinal air, nitrogen or compressed air.

In situ plants for the production of oxygen for hospital use are regarded as an interesting alternative, provided they prevent the evaporation effect which occurs in cryogenic tanks and which is responsible for evaporation losses approaching 10\% [45]. Such plants include oxygen compressors for cylinder filling operations, which operate with a single compression system cooled by a refrigerant (which is in turn cooled by air), so that oxygen is ensured to be produced at low temperature.

Centralized supply of medical gases through cryogenic tanks reduces supply costs but also increases the fixed costs of facility maintenance and investment in distribution facilities. All hospital types should be interested in optimizing the management of medical gases, regardless of size, for reasons of economic savings and environmental efficiency.

Accidents derived from the handling of high-pressure equipment are a potential risk for hospital patients and staff [46], and therefore suitable safety measures regarding oxygen supply installations (mainly those of production in bulk) must be utilised accordingly [47].

A specific technology to capture, recover and purify the halogenated anaesthetic gases used in hospital operating theatres might help extend the life cycle of such anaesthetic gases up to 10 to 20 times. This way, significant savings would definitely be achieved as related to costs arising from anaesthetic gas supply and from prevention of greenhouse emissions [48].

In any case, the existence of a control protocol [49] for medical gas installations in hospitals is a key factor to ensure a stable gas supply. Gas pipelines should therefore be monitored from the tank location to the various gas inlets along the building [50]. The remaining level in gas tanks should be appropriately displayed by the equipment. Moreover, the operating status of the gas supply plant as well as the gas pressure at each inlet in use should also be accounted for. Note that it is essential to prevent cross connections among installations involving different medical gases; the supply of carbon dioxide to a hypoxic patient might probably result in death risk. Thus, standardized inlets should accordingly be used in order to prevent cross gas connections [51].

\section{Conclusions}

For the sample set of hospitals accounted for, the results hereby reported show clear correlations among the annual consumption rates of medical gas and some of the specific variables under study. In particular, the mean annual consumption rate of medical oxygen was evidenced to be correlated to the following variables: Useful floor area, number of beds, number or workers, number of hospital discharges, number of hospital stays and number of endoscopies. On another note, the mean annual consumption rate of medicinal air showed a clear correlation to the useful floor area, the number of beds, the number of workers, the number of discharges and the number of surgeries.

In a standard hospital of 100 beds, a potential mean saving of $11.42 \%$ was estimated if a change in the supplying scheme is accomplished so that medicinal air is produced in situ by oxygen-nitrogen mixers and carbon dioxide is supplied as B50 cylinders. Furthermore, the monitoring of gas consumption together with the elimination of gas leakage would yield an additional mean cost saving of $7000 € /$ year for a standard hospital.

Hospitals exceeding 90 beds were observed to consume higher volumes of medicinal air per bed than the rest. With regard to the consumption of medicinal air per hospital discharge, hospitals accounting for more than 6000 discharges presented higher rates than those with less than this number. Finally, it was evidenced that hospitals where a higher number of surgeries were carried out showed higher consumption rates of nitrogen protoxide than those for which a lower number of surgeries 
occur; and carbon dioxide consumption was seen to be higher for hospitals with a higher number of outpatient surgeries than for those in which such types of intervention do not occur.

As an overall outcome, it should be noted that a set of variables directly related to healthcare activity (namely number of hospitalisations, number of emergency interventions, number of hospital surgeries and number of hospital discharges) should be regarded as suitable variables to quantify, size and monitor the costs arising from the use of medical gases in hospitals. It is possible to have a benchmarking system that compares the consumption of a hospital with another reference hospital by using these indicators. This is a novelty, given that there are no precedents in the scientific literature for similar indicators.

This study is valid for privately managed hospitals with less than 200 beds. Since the forms of management and pathologies treated in a private hospital are similar in all hospitals, the data can be extrapolated to other countries with similar healthcare systems.

Further research work will comprise the assessment of the environmental impact of medical gases on the operation of hospital facilities, mainly as related to the particular gases involving the generation of $\mathrm{NO}_{x}$ compounds. The study of each one of the areas of a hospital should be also considered in further depth in the future, so that the consumption of each medical assistance service can be known with a certain degree of accuracy. For that to occur, medical gas meters should be installed, which allow the attainment of homogeneous readings on which to establish internal consumption parameters.

Author Contributions: Conceptualization, J.G.-S.-C.; Formal analysis, J.G.-S.-C.; Funding acquisition, M.G.-C.; Investigation, M.G.-C., J.G.-S.-C. and L.A.M.; Methodology, J.G.-S.-C.; Resources, L.A.M.; Software, M.G.-C.; Validation, J.G.-S.-C.; Visualization, L.A.M.

Funding: This research received no external funding.

Acknowledgments: The authors wish to thank the Junta de Extremadura, the European Social Found (FEDER) and the Ministry of Education, Culture and Sports for their support towards this research. This study has been carried out through the Research Project GR-18029 linked to the VI Regional Research and Innovation Plan of the General Government of Extremadura.

Conflicts of Interest: The authors declare no conflict of interest.

\section{References}

1. Hurlé, A.D.-G. Medicinal gases, new medicines. Farm. Hosp. 2005, 29, 300-302. [CrossRef]

2. Guijarro-Gallardo, M.; Pérez-Robles, T. Gases Medicinales: Estudio de Utilización en el Ámbito Hospitalario. Bachelor's Thesis, Complutense University, Madrid, Spain, 2016.

3. Westwood, M.M.; Rieley, W. Medical gases, their storage and delivery. Anaesth. Intensive Care Med. 2012, 13, 533-538. [CrossRef]

4. Jahn, U.R.; Berendes, E. Nitrous oxide-an outdated anaesthetic. Best. Pract. Res. Clin. Anaesthesiol. 2005, 19, 391-397. [CrossRef] [PubMed]

5. Leung, M.; Chan, A.H.S. Control and management of hospital indoor air quality. Med. Sci. Monit. 2006, 12, SR17-SR23. [PubMed]

6. Shohet, I.M.; Nobili, L. Application of key performance indicators for maintenance management of clinics facilities. Int. J. Strateg. Prop. Manag. 2017, 21, 58-71. [CrossRef]

7. Chyu, M.C.; Austin, T.; Calisir, F.; Chanjaplammootil, S.; Davis, M.J.; Favela, J.; Gan, H.; Gefen, A.; Haddas, R.; Hahn-Goldberg, S.; et al. Healthcare Engineering Defined: A White Paper. J. Healthc. Eng. 2015, 6, 635-648. [CrossRef] [PubMed]

8. Kunders, G.D. Hospitals: Facilities Planning and Management; Tata McGraw-Hill Education: New Delhi, India, 2004.

9. Harsoor, S.S.; Bhaskar, S.B. Designing an ideal operating room complex. Indian J. Anaesth. 2007, 51, $193-199$.

10. Agila Galvez, W.E.; Correa Crespo, L.C.; Vélez Ozaeta, H.O. Automation of Medical Gas System in a 400-Bed Hospital Dialysis Area; Escuela Superior Politécnica del Litoral: Guayaquil, Ecuador, 2017.

11. Zelaya Castro, J.C. Criterios de Diseño y Cálculo de Sistemas de Suministro y Distribución de Gases Medicinales Para un Hospital; Universidad Nacional de Ingeniería: Lima, Peru, 2013. 
12. Sánchez Lara, E.F.; Zacarías Pérez, J.S. Sistema de Conducción de Gases de un Hospital de 120 Camas Situado en la Región Costa que Pertenece al Ministerio de Salud Pública del Ecuador. Bachelor's Thesis, Escuela Politécnica Nacional, Quito, Ecuador, 2010.

13. Morua-González, L.M. Anteproyecto Para la Creación de una Empresa Para Suministro de Oxígeno Medicinal a Hospitales del Distrito Federal. Ph.D. Thesis, Instituto Politécnico Nacional, Ciudad de México, Mexico, 2009.

14. French Red Cross. A Source of Design Reference Standards Handbook to Build an Hospital; Construction Délegation: Malé, Maldives, 2006.

15. Ciarapica, F.E.; Giacchetta, G.; Paciarotti, C. Facility management in the healthcare sector: Analysis of the Italian situation. Prod. Plan. Control 2008, 19, 327-341. [CrossRef]

16. García-Sanz-Calcedo, J.; Gómez-Chaparro, M. Quantitative Analysis of the Impact of Maintenance Management on the Energy Consumption of a Hospital in Extremadura (Spain). Sustain. Cities Soc. 2017, 30, 217-222. [CrossRef]

17. Dettenkofer, M.; Kümmerer, K.; Schuster, A.; Mühlich, M.; Scherrer, M.; Daschner, F.D. Environmental auditing in hospitals: Approach and implementation in a university hospital. J. Hosp. Infect. 1997, 36, 17-22. [CrossRef]

18. Gómez, A.; Carnero, M.C. Decision Support System for maintenance policy optimization in medicinal gases subsystems. IFAC-PapersOnLine 2016, 49, 268-273. [CrossRef]

19. Girón, E.G. Sistema de gases médicos: Una guía práctica para el diseño. Ing-Novación 2012, 3, 5-26.

20. Department of Health Gateway Reviews, Estates and Facilities Division. Healthcare Premises Cost Guides (HPCGs); Department of Health: Leeds, UK, 2010.

21. World Health Organization. Safe Management of Wastes from Health-Care Activities; Chartier, Y.J.E., Pieper, U., Prüss, A., Rushbrook, P., Stringer, R., Townend, W., Wilburn, S., Zghondi, R., Eds.; World Health Organization: Geneva, Switzerland, 2014.

22. Eckelman, M.J.; Sherman, J. Environmental impacts of the US health care system and effects on public health. PLoS ONE 2016, 11, e0157014. [CrossRef] [PubMed]

23. Hewitt, M.; Molthan-Hill, P.; Lomax, R.; Baddley, J. Supporting the UN's Sustainable Development Goals: Reconceptualising a 'sustainable development assessment tool' for the health and care system in England. Perspect. Public Health 2018. [CrossRef] [PubMed]

24. McLaughlin, S.; Dagenais, D.A. Medical Gas Cylinder and Bulk Tank Storage; The American Society for Healthcare Engineering of the American Hospital Association: Chicago, IL, USA, 2012.

25. Gadani, H.; Vyas, A. Anesthetic gases and global warming: Potentials, prevention and future of anesthesia. Anesth. Essays Res. 2011, 5, 5-10. [CrossRef] [PubMed]

26. Brown, L.H.; Buettner, P.G.; Canyon, D.V. The energy burden and environmental impact of health services. Am. J. Public Health 2012, 102, e76-e82. [CrossRef] [PubMed]

27. Air Products and Chemicals, Inc. Available online: http://www.carburos.com/Products/Gases/SpecialtyGases/Medicinal-Gases.aspx (accessed on 18 May 2018).

28. Baum, J.A. The carrier gas in anaesthesia: Nitrous oxide/oxygen, medical air/oxygen and pure oxygen. Curr. Opin. Anesthesiol. 2004, 17, 513-516. [CrossRef]

29. Morgenstern, P.; Li, M.; Raslan, R.; Ruyssevelt, P.; Wright, A. Benchmarking acute hospitals: Composite electricity targets based on departmental consumption intensities? Energy Build. 2016, 118, 277-290. [CrossRef]

30. García-Sanz-Calcedo, J.; Al-Kassir, A.; Yusaf, T. Economic and Environmental Impact of Energy Saving in Healthcare Buildings. Appl. Sci. 2018, 8, 440. [CrossRef]

31. Sedgwick, P. Pearson's correlation coefficient. Br. Med. J. 2012, 345, e4483. [CrossRef]

32. Turakhia, R.P.; Daasch, W.R.; Lurkins, J. Changing test and data modeling requirements for screening latent defects as statistical outliers. IEEE Des. Test Comput. 2006, 23, 100-109. [CrossRef]

33. Glantz, S.A.; Slinker, B.K.; Neilands, T.B. Primer of Applied Regression and Analysis of Variance; McGraw-Hill: New York, NY, USA, 1990.

34. Royston, J.P. Some techniques for assessing multivarate normality based on the Shapiro-Wilk W. Appl. Stat. 1983, 32, 121-133. [CrossRef] 
35. Nordstokke, D.W.; Zumbo, B.D.; Cairns, S.L.; Saklofske, D.H. The operating characteristics of the nonparametric Levene test for equal variances with assessment and evaluation data. Pract. Assess. Res. Eval. 2011, 16, 1-15.

36. Chen, Y.Y.; Chen, G.; Gou, Q.Y. Maintenance of medical equipment in hospital. Inf. Med. Equip. 2005, 5, 020.

37. Tabish, S.A.; Jeelani Qadiri, G.H. Cost evaluation of medical gases facility at a tertiary care teaching medical institute. Health Popul. 1994, 17, 219-229.

38. Popa, I.; Ștefan, S.C. Modeling the Impact of Short-Term and Long-Term Determinants of European Health Systems' Performance: A Panel Data Approach. Sustainability 2017, 9, 1595. [CrossRef]

39. González, A.; García-Sanz-Calcedo, J.; Salgado, D.R. Quantitative Determination of Potable Cold Water Consumption in German Hospitals. Sustainability 2018, 10, 932. [CrossRef]

40. García Sanz-Calcedo, J.; Monzón González, P. Analysis of the economic impact of environmental biosafety works projects in healthcare centres in Extremadura (Spain). Dyna 2014, 81, 100-105. [CrossRef]

41. Schumacher, S.D.; Brockwell, R.C.; Andrews, J.J.; Ogles, D. Bulk liquid oxygen supply failure. Anesthesiology 2004, 100, 186-189. [CrossRef] [PubMed]

42. DH Estates and Facilities Directorate. Medical Gases Health Technical Memorandum 02-01: Medical Gas Pipeline Systems; The Stationery Office: London, UK, 2006.

43. Herrera-Galán, M. Management audit applied to the maintenance department in hospital facilities. Ing. Mec. 2017, 20, 152-159.

44. Srivastava, U. Anaesthesia Gas Supply: Gas Cylinders. Indian J. Anaesth. 2013, 57, 500-506. [CrossRef] [PubMed]

45. Huang, J.; Shang, L.; Tang, G. Safe Use of Liquid Medical Oxygen Cryogenic Tank. Low Temp. Spec. Gases 2012, 2, 014.

46. Bejinariu, C.; Darabont, D.C.; Baciu, E.R.; Georgescu, J.S.; Bernevig-Sava, M.A.; Baciu, C. Considerations on Applying the Method for Assessing the Level of Safety at Work. Sustainability 2017, 9, 1263. [CrossRef]

47. Feeley, T.; Mcclelland, K.; Malhotra, I. The hazards of bulk oxygen delivery systems. Lancet 1975, 305, 1416-1418. [CrossRef]

48. Byrick, B. Reclamation of Exhaled Vapour Anesthetic: Evaluation of a New Technology. Can. J. Anesth. Available online: www.bluezone.ca (accessed on 30 April 2018).

49. Kim, H.; Kang, J. Dynamic Group Management Scheme for Sustainable and Secure Information Sensing in IoT. Sustainability 2016, 8, 1081. [CrossRef]

50. Hick, J.L.; Hanfling, D.; Burstein, J.L.; DeAtley, C.; Barbisch, D.; Bogdan, G.M.; Cantrill, S. Health care facility and community strategies for patient care surge capacity. Ann. Emerg. Med. 2004, 44, 253-261. [CrossRef] [PubMed]

51. Thomas, A.N.; Hurst, W.; Saha, B. Interchangeable oxygen and air connectors. Anaesthesia 2001, 56, 1203-1216. [CrossRef]

(C) 2018 by the authors. Licensee MDPI, Basel, Switzerland. This article is an open access article distributed under the terms and conditions of the Creative Commons Attribution (CC BY) license (http://creativecommons.org/licenses/by/4.0/). 